\title{
Hydrogen Physisorption on BNC Heterostructures: A Systematic Theoretical Study
}

\author{
D.V. Bogdanovich, A.I. Tsar'kova, I.K. Petrushenko*
}

\author{
Irkutsk National Research Technical University, 83, Lermontov St., 664074 Irkutsk, Russia
}

(Received 21 March 2021; revised manuscript received 09 August 2021; published online 20 August 2021)

\begin{abstract}
Herein, we study hydrogen adsorption on graphene, hexagonal boron nitride (h-BN) and their BNC (boron-nitrogen-carbon) heterostructures by using DFT. Different combinations of carbon and boron nitride moieties in one sheet, as well as the influence of carbon to $\mathrm{BN}$ ratio on the hydrogen adsorption, have been systematically investigated. We involve theoretical consideration of adsorption energies $\left(E_{a}\right)$, electrostatic potential maps, independent gradient model analysis as well as Monte-Carlo simulations. We have established that for the 'hollow' adsorption, a minor difference for graphene and BNCs $(\sim 0.0$ (vertical) and 0.1 (horizontal adsorption) $\mathrm{kJ} / \mathrm{mol}$ ) exists, whereas BNCs exhibit sufficiently higher $E_{a}$ compared with h-BN $(0.3$ and $0.7 \mathrm{~kJ} / \mathrm{mol})$. For the studied 'top' and 'bond' adsorption, changes are more pronounced. The excess reaches 0.4 and $0.9 \mathrm{~kJ} / \mathrm{mol}$ ('bond'), as well as 0.8 and $1.0 \mathrm{~kJ} / \mathrm{mol}$ ('top'), for graphene and h-BN, respectively. Hydrogen adsorption isotherms show increased hydrogen uptake by BNCs in comparison with their pristine counterparts.
\end{abstract}

Keywords: DFT, Heterostructure, Graphene, Adsorption, Hydrogen storage.

DOI: 10.21272/jnep.13(4).04026

\section{INTRODUCTION}

Nowadays, hydrogen is considered as one of the most promising 'green' energy sources, because of the fact that it is abundant in nature, and the product of its combustion is water [1]. To employ the ultimate advantages of hydrogen as a fuel, a lot of aspects should be carefully considered. They include massive hydrogen production, purification, storage, and delivery. The issue of designing novel materials and systems for $\mathrm{H}_{2}$ storage is of primary importance. Besides two obvious storage methods, namely $\mathrm{H}_{2}$ storage in the gaseous form or as a liquid, researchers can highlight two large fields involving solidstate materials as adsorbents [2,3]. The physisorption and chemisorption methods are up-to-date ones, and each of them has certain advantages and shortcomings. Basically, they stem from the natural background of these processes: physisorption, mainly determined by van der Waals (vdW) forces, is a weak interaction; chemisorption is much stronger and is characterized by the presence of chemical bonds between the adsorbate and the adsorbent. Therefore, physisorption of $\mathrm{H}_{2}$ on the adsorbent is very weak and requires low temperatures and/or high pressures to ensure reasonable storage stability. On the other hand, physisorption represents a high degree of reversibility in contrast to chemical adsorption, which suits well for long-term storage.

Graphene [4], a two-dimensional (2D) allotrope of carbon, is a popular theme of research nowadays due to its unique structural [5], mechanical [6,7], electrical [8], optical [9], and thermal [10] properties. It is a light material, stable and robust, and, therefore, can be used as a solid-state adsorbent. Hexagonal boron nitride (h$\mathrm{BN})$, a graphene counterpart, has also received considerable attention in many fields of science [11]. Both well-known nanomaterials have been extensively investigated in relation to the adsorption of molecules and nanoclusters $[12,13]$. Very recently, 2D hybrids made from graphene and h-BN moieties have been proposed and synthesized [14-20]. Although the physics and
PACS numbers: 68.43._h, 21.60.De

chemistry of interesting hybrid structures are relatively well understood today, the interaction of hydrogen molecules with their surfaces has been sporadically reported. We should note our previous work, in which $\mathrm{H}_{2}$ adsorption on a hybrid structure with only one heterointerface was studied [21]. The recent comprehensive work of Velázquez-López et al. has studied various BNC coronene-like structures, but their primary aim was to determine their $\mathrm{CO}$ sensor properties [22]. Besides this, the interaction of $\mathrm{O}_{2}$ and $\mathrm{NO}_{2}$ molecules with carbon-boron nitride single-walled nanotubes was investigated [23, 24].

To investigate $\mathrm{H}_{2}$ adsorption properties of BNC heterostructures in detail, in this work, we systematically study the evolution of graphene towards h-BN via design of the intermediate structures (Fig. 1). To obtain various BNC models, we vary $\mathrm{B}+\mathrm{N}$ to $\mathrm{C}$ atomic ratio $(R)$. Determination of the optimal doping ratio is of importance for the increase in the hydrogen uptake by solid-state adsorbents as we expect significant changes in the electronic density distribution of BNC structures compared with pristine graphene and h-BN. We suppose that the interactions between the permanent dipoles (BNCs) and induced dipoles (polarized $\mathrm{H}_{2}$ molecules) can give rise to advanced storage properties of such BNCs. The results could be specifically significant for promoting the use of heterostructures as nanoscale platforms for $\mathrm{H}_{2}$ storage.

\section{COMPUTATIONAL DETAILS}

Full geometry optimization of all structures has been performed at the PBE/SVP [25-27] level of theory, using the Orca 4.1.0 program [28]. The dispersion correction of Grimme et al. (D3) [29] was used to properly treat the dispersion interactions. PBE has been shown to be a very reliable density functional that suits well for adsorption studies [21, 30-32]. A coronene $\left(\mathrm{C}_{24} \mathrm{H}_{12}\right)$ molecule was chosen as a graphene sheet model, which was successfully involved in our previous papers [21, $31]$ and elsewhere [22, 33]. Many works considered

\footnotetext{
*igor.petrushenko@istu.edu
} 


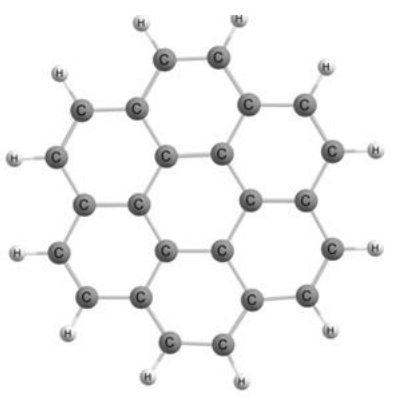

C24 (graphene), $R=0$

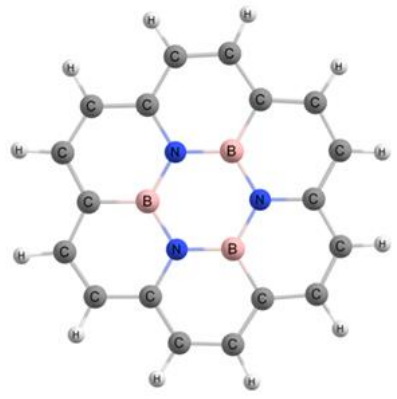

B3N3, $R=0.33$

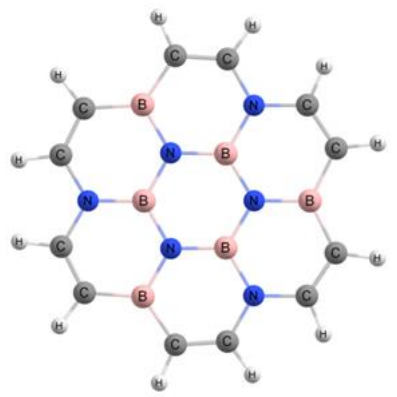

$\mathrm{B} 6 \mathrm{~N} 6, R=1$

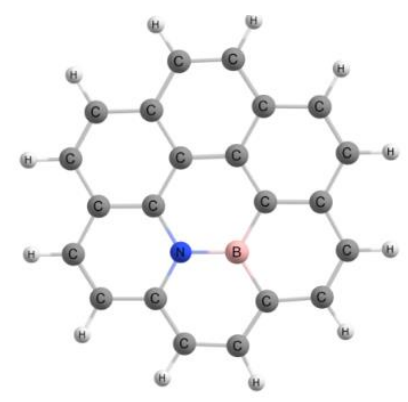

$\mathrm{B} 1 \mathrm{~N} 1, R=0.09$

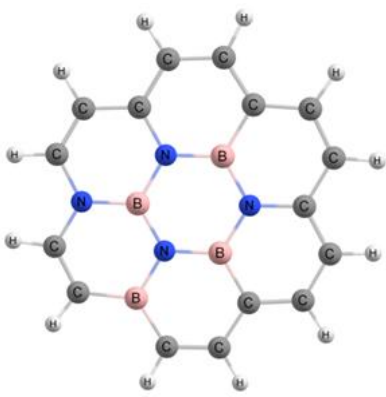

$\mathrm{B} 4 \mathrm{~N} 4, R=0.5$

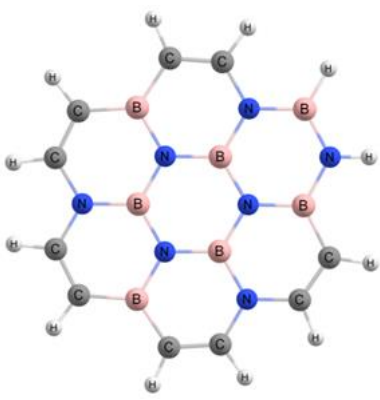

$\mathrm{B} 7 \mathrm{~N} 7, R=1.4$

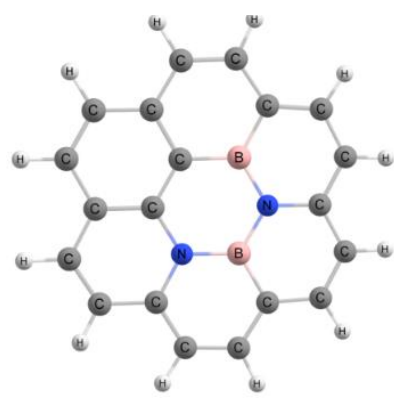

$\mathrm{B} 2 \mathrm{~N} 2, R=0.2$

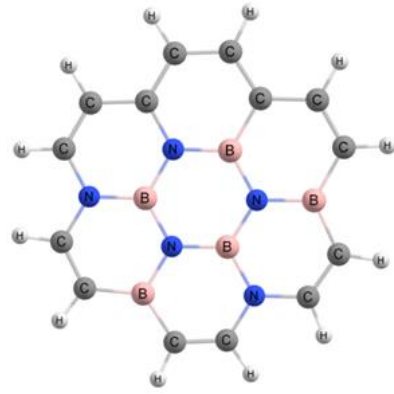

$\mathrm{B} 5 \mathrm{~N} 5, R=0.71$

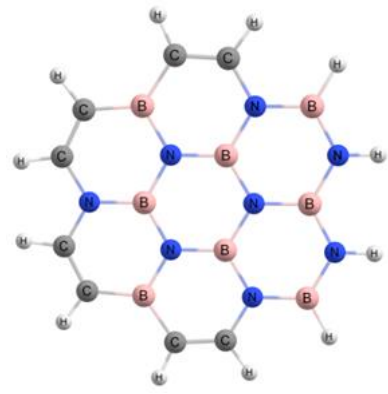

$\mathrm{B} 8 \mathrm{~N} 8, R=2$

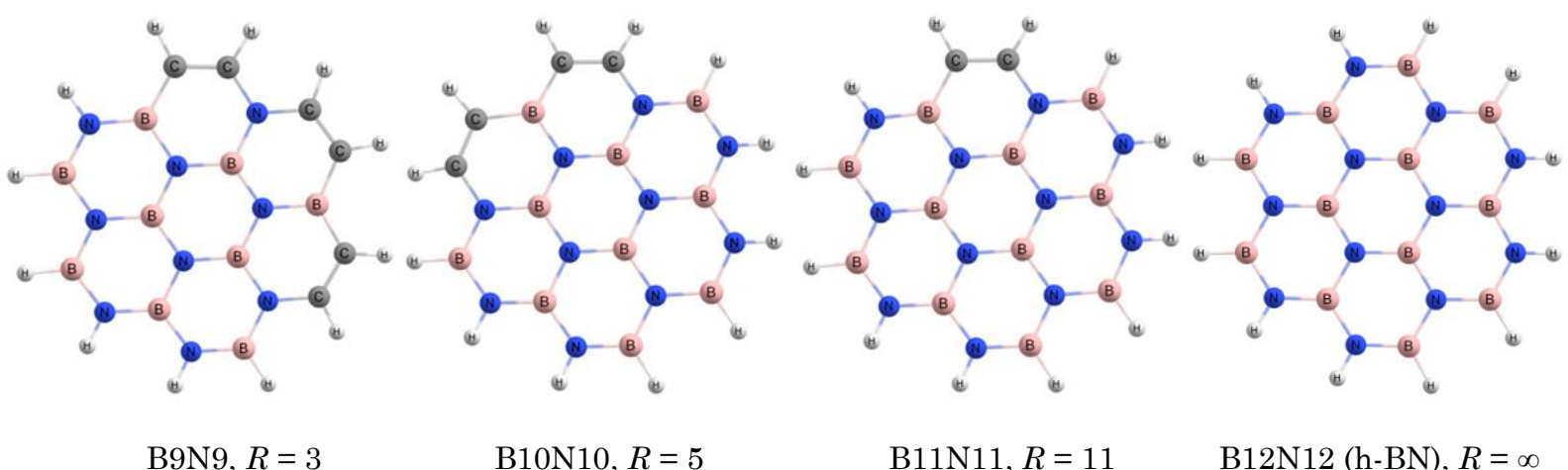

Fig. 1 - Graphene, h-BN and BNC models studied in this work. $R$ denotes $\mathrm{B}+\mathrm{N}$ to $\mathrm{C}$ atomic ratio. Atomic color scheme: grey carbon, white - hydrogen, blue - nitrogen, light red - boron

a coronene-based model as a minimal model which preserves the properties of graphene [34, 35]. Starting from the coronene model, we add couples of $\mathrm{B}$ and $\mathrm{N}$ atoms in a step-by-step manner. The first BNC model was designed by placing heteroatoms in the central hexagon ring. The $R$ value denotes $(\mathrm{B}+\mathrm{N}) / \mathrm{C}$ atomic ratio. The stabilities of all models were investigated by binding energies $\left(E_{b}\right)$ per atom calculations, according to Eq. (1):

$$
E_{b}=1 / n \times\left(E_{t}-\Sigma E_{i} N_{i}\right),
$$

where $E_{t}$ is the total energy of the respective BNC model, $N_{i}$ is the number of the $i$-th element, $E_{i}$ is the total anergy of the $i$-th atom, $n$ is the total number of atoms in the system [20].

The procedure of adsorption energy $\left(E_{a}\right)$ calculations is as follows. First, all models as well as $\mathrm{H}_{2}$ molecules were fully optimized at the PBE-D3/SVP level of theory. Then the geometries of these species were frozen. Second, we fixed the perpendicular orientation of a hydrogen molecule relative to the studied systems and investigated 'hollow', 
'bond', and 'top' adsorption sites (see Fig. 2).

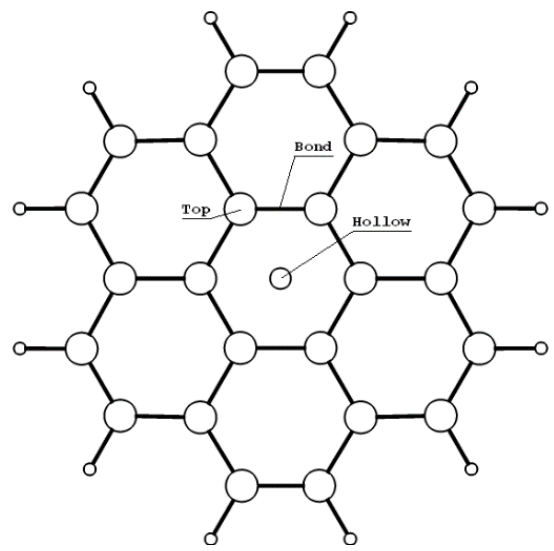

Fig. 2-Positions of hydrogen adsorption on the graphene model. Large balls are $\mathrm{C}$ atoms, small balls are $\mathrm{H}$ atoms. The central mark ('hollow') is used for easy reference

Third, we fixed the parallel orientation of hydrogen in relation to the adsorbents' planes and studied the same adsorption sites. The distance between $\mathrm{H}_{2}$ and all studied models $(d)$ is defined as the length of a perpendicular line dropped from the hydrogen center-of-mass to the plane of the studied system. Finally, we varied the distance from 5.5 to $2 \AA$ and calculated single-point $E_{a}$ using Eq. (2):

$$
E_{a}=E\left(\text { adsorbent } / \mathrm{H}_{2}\right)-E(\text { adsorbent })-E\left(\mathrm{H}_{2}\right),
$$

where $E$ (adsorbent/ $\left.\mathrm{H}_{2}\right), E\left(\mathrm{H}_{2}\right)$, and $E$ (adsorbent) denote the single-point energy of the $\mathrm{H}_{2}$ /adsorbent complex, the total energy of the hydrogen molecule and the adsorbent, respectively. In all calculations made with Eqs. (1), (2), negative values were obtained, indicating that the species formed are more stable than their separate constituents. We then drew the $E_{a}$ vs. $d$ plots of a Lennard-Jones type for all studied models, the minima of which correspond to adsorption energies (see Fig. 3 as an example).
In order to obtain hydrogen adsorption isotherms, we used grand canonical Monte-Carlo (GCMC) simulations following the Metropolis' sampling scheme [36, 37]. The universal force field was employed [38]. The temperatures $(T)$ were fixed at 77 and $300 \mathrm{~K}$. The pressures $(P)$ from $10 \mathrm{kPa}$ to $10 \mathrm{MPa}$ were used. Periodic boundary conditions (PBC) were applied to all models. The inplane cell parameters were 25.56 and $14.76 \AA$, while the lattice constant in the $z$ direction was $25 \AA$. To visualize all studied structures, we used the Chemcraft software [39]. The Multiwfn 3.5 program [40] was used for the independent gradient model (IGM) analysis [41, 42].

\section{RESULTS AND DISCUSSION}

We start from the analysis of the structural stability of the adsorbents studied herein. The binding energy per atom $\left(E_{b}\right)$ for every model was calculated using Eq. (1) (Table 1).

The definition of $E_{b}$ represents a measure of the cohesive strength of adsorbent models. Higher absolute values of $E_{b}$ correspond to a stronger cohesive strength of the system, and, thus, define a higher structural stability. The obtained results (see Table 1) show that the graphene model has the largest negative $E_{b}$ of $-7.48 \mathrm{eV} /$ atom, and, therefore, it is the most stable. To check that our DFT-D3 results are not spurious, we perform comparison with earlier predictions as well as available experimental data. The $E_{b}$ energies are in the range from -7.2 to -7.9 (theory) $[43,44]$ and -7.43 eV/atom (experiment) [43]. We found out that the obtained results are in a very good accordance with those previously reported.

The h-BN model has the lowest $E_{b}$ value of $-5.87 \mathrm{eV}$. For these structures, less reliable experimental data exist. The result of Albe of -6.527 for h-BN [45] and the experimental value for cubic-BN of -6.6 eV/atom [46] are also close to our value. It presumes lower structural rigidity than that of graphene. The $E_{b}$ values for other studied systems fall between them (Table 1).

Table 1 - Binding energies $\left(E_{b}\right)$ per atom $(\mathrm{eV})$ for the studied adsorbents

\begin{tabular}{|c|c|c|c|c|c|c|}
\hline $\mathrm{C} 24$ & B1N1 & $\mathrm{B} 2 \mathrm{~N} 2$ & B3N3 & B4N4 & B5N5 & $\mathrm{B} 6 \mathrm{N6}$ \\
\hline-7.48 & -7.30 & -7.14 & -7.01 & -6.85 & -6.70 & -6.56 \\
\hline & 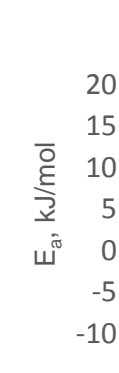 & \{ & $\mathrm{C} 2$ & $\mathrm{~d}, \AA$ & $\omega$ & \\
\hline
\end{tabular}

\begin{tabular}{|c|c|c|c|c|c|}
\hline B7N7 & B8N8 & B9N9 & B10N10 & B11N11 & B12N12 \\
\hline
\end{tabular}

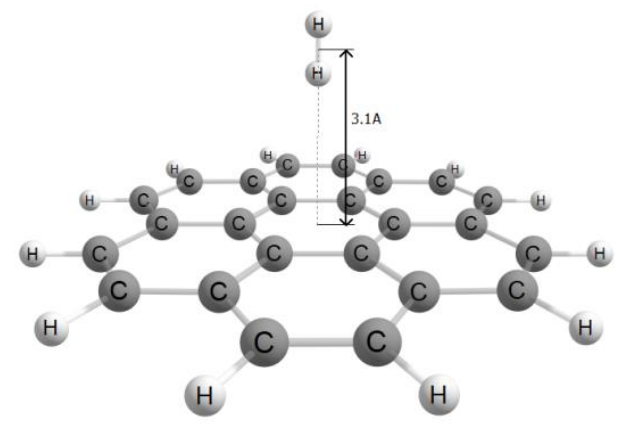



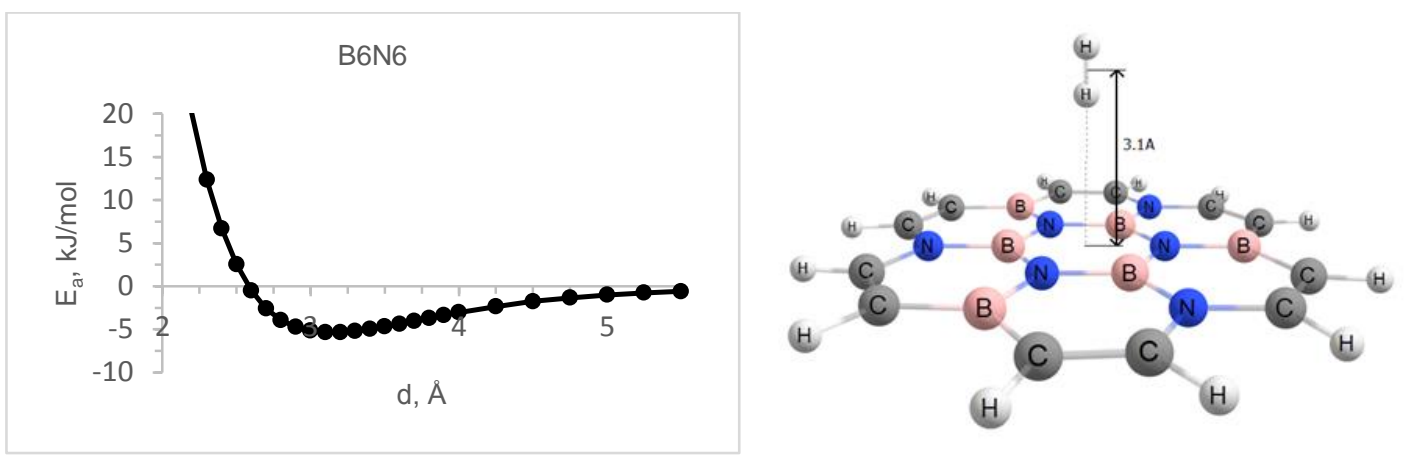

$\mathrm{b}$
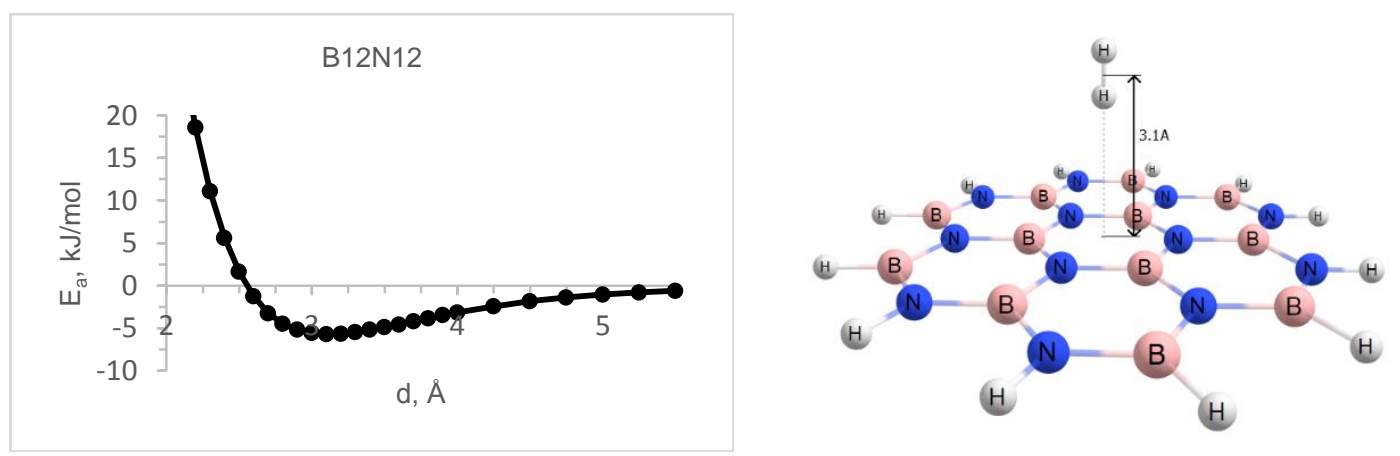

Fig. $3-E_{a}$ vs. $d$ graphs of a Lennard-Jones type for C24 (a), B6N6 (b), B12N12 (c). The position of $\mathrm{H}_{2}$ adsorption is the 'hollow', vertical one

It is worth noting that graphene has the largest structural stability among BN-substituted species because of $\pi$-electron delocalization effects as it was observed earlier [20]. As a whole, all studied adsorbents exhibit negative $E_{b}$ values that confirms their structural stabilities. We further study the hydrogen adsorption on the employed models (Fig. 1). The case of graphene is used as an example. There exist six possible configurations for hydrogen adsorption: three vertical positions ('hollow' (in the center of a six-membered ring), 'bond' (in the center of the $\mathrm{C}-\mathrm{C}$ bond), and 'top' (on the $\mathrm{C}$ atom)) and three horizontal positions (Fig. 2). When the vertical orientation of the molecule is considered, it is perpendicularly placed to the plane of graphene. On the other hand, the horizontal orientation includes parallel mutual location of hydrogen and graphene. Fig. 4

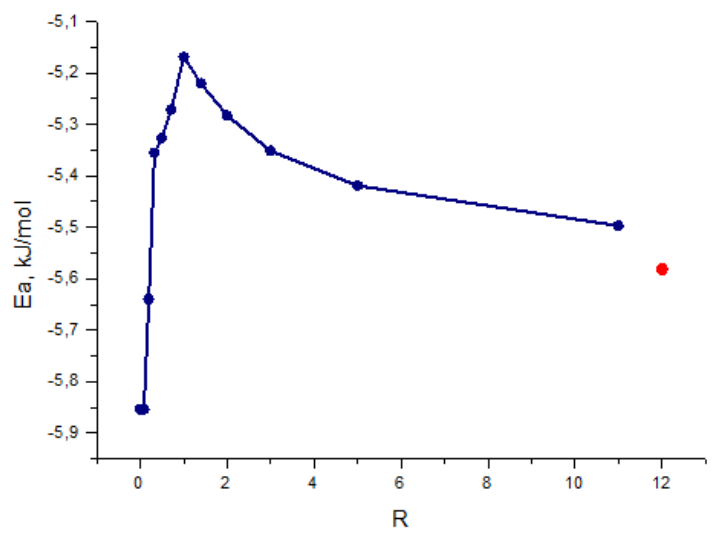

a

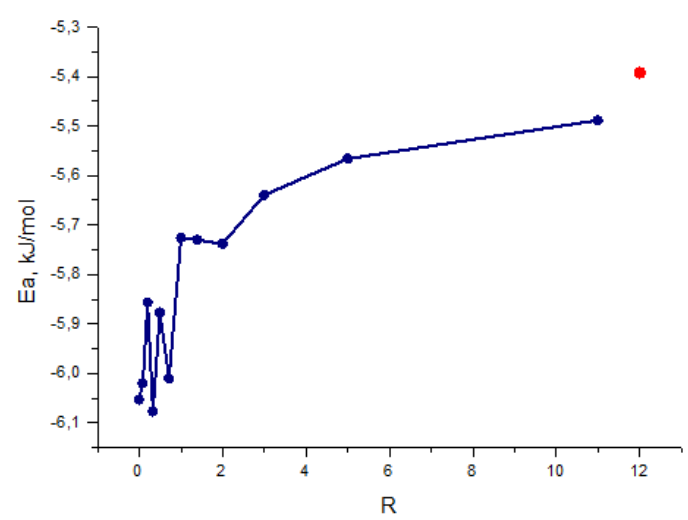

b

Fig. $4-E a$ vs. $R$ graphs for vertical (a) and horizontal (b) adsorption ('hollow' adsorption). $R$ denotes $\mathrm{B}+\mathrm{N}$ to $\mathrm{C}$ atomic ratio. The red circle denotes $\mathrm{B} 12 \mathrm{~N} 12$

shows the adsorption energies of $\mathrm{H}_{2}$ on all studied sheets in dependence to $R$. We check two adsorption positions, vertical as well as horizontal one, depending on the mutual arrangement of the hydrogen molecule and the adsorbent.

For graphene, the horizontal approaching is slightly more energetically favorable in comparison with the vertical one. The equilibrium distances between hydrogen molecules and the adsorbents in both cases are in the range of 3.0-3.1 $\AA$. On the other hand, the vertical adsorption is more favorable for h-BN. For the vertical adsorption, the observed $E_{a}$ values fall between graphene and h-BN values. $\mathrm{B}$ and $\mathrm{N}$ doping does not improve adsorption in this case. We can see some oscilla- 
tions for $E_{a}$ in the case of horizontal adsorption (the field of $R \leq 2$ ), however, they represent almost equal values. Ongoing to larger $R$ values, one can see more separate $E_{a}$ values, and the interaction between $\mathrm{H}_{2}$ molecules and adsorbent models gradually decreases. The major changes are attributed to the incomplete replacement of $\mathrm{C}$ atoms in six-membered rings. Besides this, the propagation of $\mathrm{B}$, $\mathrm{N}$ substitution to the peripheral rings does not substantially change the $E_{a}$ values. The IGM approach will help us interpret the cause of that, as we will see below. The highest $E_{a}$ values are -5.85 and $-6.08 \mathrm{~kJ} / \mathrm{mol}$ for graphene and B3N3, respectively.

Fig. 5 shows a more diverse scene: we can easily detect the separate minima for certain heterostructures.

We study vertical adsorption as well as approaching of two horizontal $\mathrm{H}_{2}$ adsorptions, when the axis of the
$\mathrm{H}_{2}$ molecule is along the underlying adsorbent bond (horizontal adsorption 1) and is perpendicular to it (horizontal adsorption 2). The B1N1 (vertical adsorption) and B2N2 (two cases of horizontal adsorption) models present the largest absolute $E_{a}$ values of -5.78 and $-5.45,-5.37 \mathrm{~kJ} / \mathrm{mol}$, respectively. As a whole, all three graphs are similar, except the distinct maximum for $\mathrm{B} 6 \mathrm{~N} 6$ in the case of vertical adsorption. For $R \geq 4$ values we observe the nearly equal results.

Finally, we study 'Top' adsorption. We highlight one vertical position (over the B atom for heterostructures) as well as two horizontal ones, which imply two mutually perpendicular orientations of the hydrogen molecule related to underlying $\mathrm{B}, \mathrm{N}$, or $\mathrm{C}$ atoms (Fig. 6). We can note the similar feature for three graphs, namely a plateau-like branch of the graphs when $R \geq 4$.

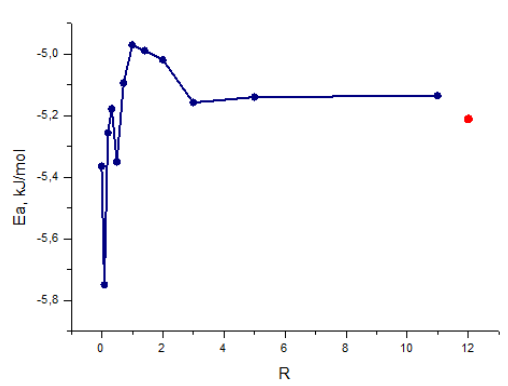

a

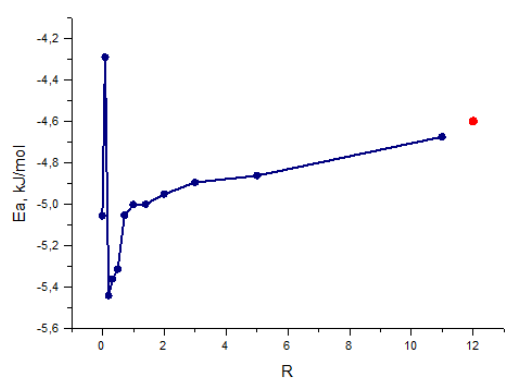

$\mathrm{b}$

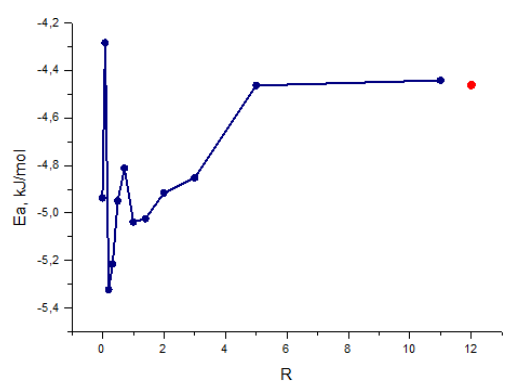

c

Fig. $5-E_{a}$ vs. $R$ graphs for vertical (a), horizontal 1 (b) and horizontal 2 (c) adsorption ('bond' adsorption). $R$ denotes $\mathrm{B}+\mathrm{N}$ to $\mathrm{C}$ atomic ratio. The red circle denotes B12N12

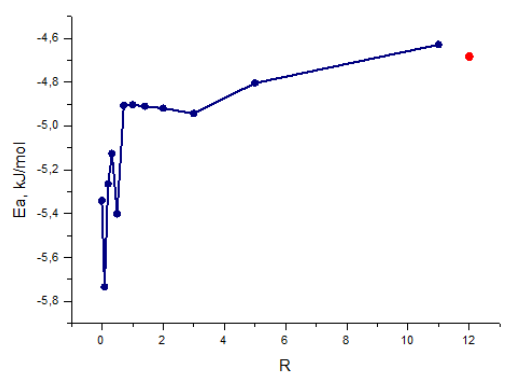

a

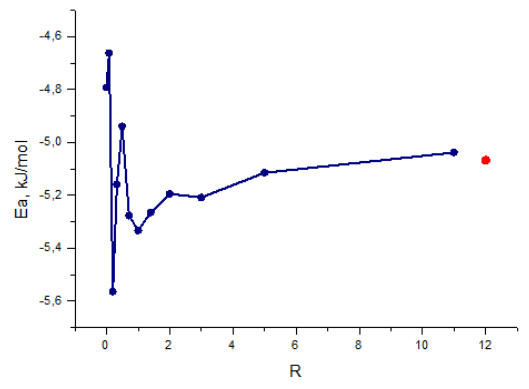

$\mathrm{b}$

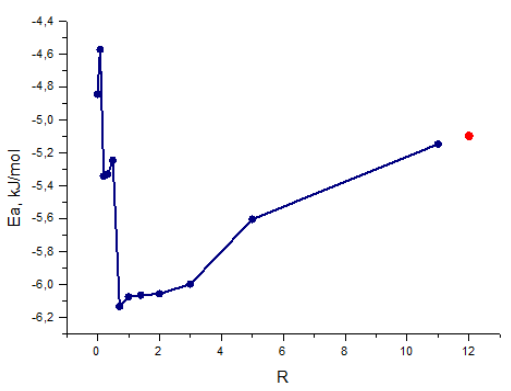

C

Fig. $6-E_{a}$ vs. $R$ graphs for vertical (a), horizontal 1 (b) and horizontal 2 (c) adsorption ('Top' adsorption). $R$ denotes $\mathrm{B}+\mathrm{N}$ to $\mathrm{C}$ atomic ratio. The red circle denotes B12N12

It corresponds to the case when the central ring of graphene is fully substituted, and we further propagate the $\mathrm{B}$ and $\mathrm{N}$ atoms introducing to peripheral area of the initial graphene model. Besides this, some controversial results are obtained for graphene and h-BN structures. For vertical adsorption, $E_{a}$ (graphene) $>E_{a}$ (h$\mathrm{BN}$ ); for the cases of horizontal adsorption, we observe the reverse situation. Such a diversity of adsorption energies was reported earlier. For example, the work of Mpourmpakis et al. specially studied boron nitride and carbon nanotubes to figure out, which nanotubes are preferable for the $\mathrm{H}_{2}$ adsorption [47].

For the vertical adsorption on B1N1, maximal $E_{a}$ of $5.78 \mathrm{~kJ} / \mathrm{mol}$ was obtained. The calculated $E_{a}$ for horizontal 1 and horizontal 2 adsorption are equal to -5.58 (B2N2) and -6.12 (B5N5) kJ/mol, respectively. All these structures are composed of six-membered rings, which include $\mathrm{B}, \mathrm{N}$, and $\mathrm{C}$ atoms rather than 'pure' carbon or boron nitride rings. To validate our results, we compare them with this experimental value of $-4.6 \mathrm{~kJ} / \mathrm{mol}$ obtained by Mattera et al. [48]. We collect all $E_{a}$ obtained and determine the lower and the upper limits as $\sim-5.4$ and $-6.1 \mathrm{~kJ} / \mathrm{mol}$, respectively. To directly compare our theoretical predictions with experimental data, we must correct $E_{a}$ values by adding the zero-point energy (ZPE) of the adsorbed $\mathrm{H}_{2}$ molecule, which is determined to be $\sim 0.6 \mathrm{~kJ} / \mathrm{mol}$ [49]. The lower corrected value, $4.8 \mathrm{~kJ} / \mathrm{mol}$, is in very good agreement with the experimental result. Other results obtained herein are somewhat higher, which is in line with previous observations that the dispersion corrected DFT methods overestimate $E_{a}$ energies. However, the present results are rather close to the experimental value in contrast to DFT-D results of $-9.5 \mathrm{~kJ} / \mathrm{mol}$ obtained elsewhere [50]. They are also in line 
with the series of results of Costanzo et al. (vdW-corrected PBE functional), which indicates good agreement of the obtained data with the experimental result [49]. An important issue we should mention is the so-called basis set superposition error (BSSE) correction. As our results are in good agreement with those obtained experimentally or by more sophisticated quantum-chemistry methods like CCSD(T) [51] and MP2 [52], we do not employ any BSSE correction.

It is important to note that we deliberately introduce heteroatoms into the graphene framework, and, thus, design heterostructures. Despite the fact that graphene and h-BN are quite similar in their characteristics $\left(E_{a}\right)$, one can reshuffle carbon and boron nitride moieties, and, thus, obtain heterostructures which may exceed adsorption properties of pristine counterparts. In such a way we attempt to change the local dipole moments on the surface of adsorbents and enhance interactions. We make the electrostatic potential maps (EPMs) for several

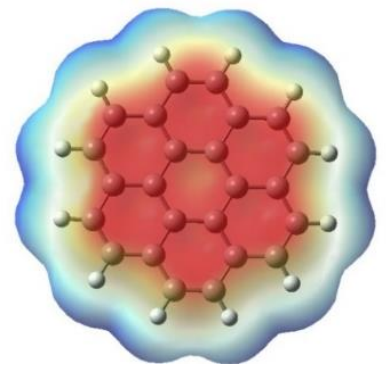

(a) Graphene (0.0002)

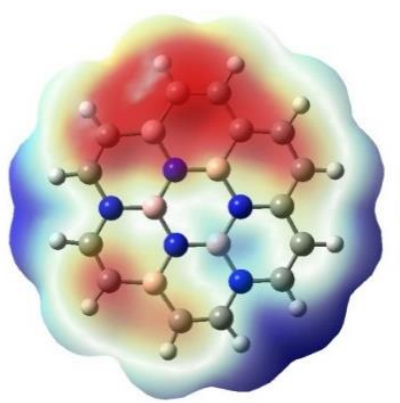

(c) B5N5 (3. 2110)

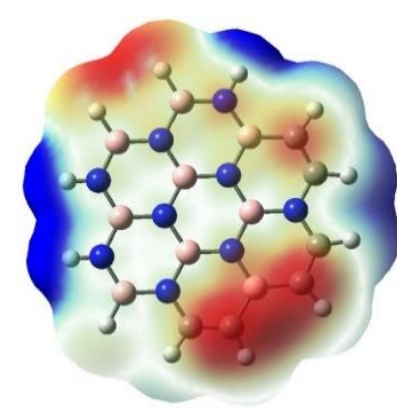

(e) B9N9 (0.7256)

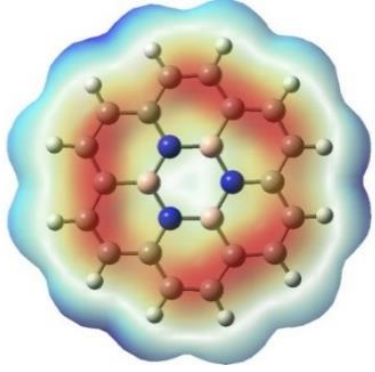

(b) B3N3 (0.0097)

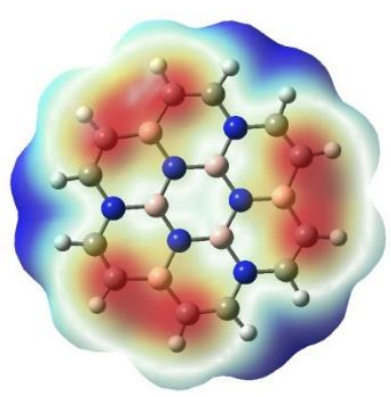

(d) B6N6 (0.01092)

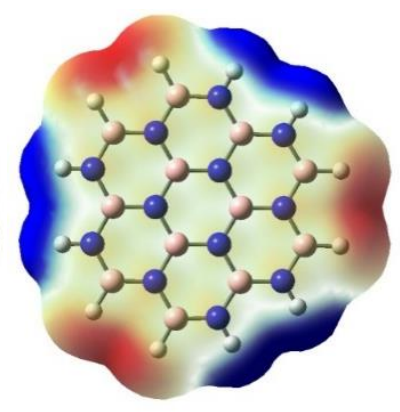

(f) $\mathrm{B} 12 \mathrm{~N} 12(\mathrm{~h}-\mathrm{BN})(0.0094)$
Fig. 7 - Calculated EPMs of pristine graphene (a), B3N3 (b), B5N5 (c), B6N6 (d), B9N9 (e), B12N12 (f) mapped with the 0.0004 a.u. isodensity. Red and deep blue colors represent the most negative and most positive regions of electrostatic potential, respectively. Atomic color scheme: grey - carbon, white hydrogen, blue - nitrogen, light red - boron. Dipole moments (Debye) are given in parentheses

involved models to illustrate the changes introduced by heteroatoms doping.

A uniform distribution of electron density can be clearly observed in the central area of graphene (see Fig. 7a). An electron-depleted central area can be observed for both $\mathrm{B} 3 \mathrm{~N} 3$ and B6N6. However, for B6N6 we may note three distinct separate electron-rich areas. In some cases, hydrogen adsorption on these structures yields maximal $E_{a}$ (Fig. 6). B9N9, in turn, exhibits the irregular pattern in electronic density distribution. In general, its adsorption behavior is much closer to that of $\mathrm{h}-\mathrm{BN}$.

The latter is characterized by an almost uniform distribution of electron density in the central area (Fig. 7f). A variety of magnitudes of the dipole moments can be observed for the studied structures. B5N5, for example, exhibits the largest dipole moment as well as the superior $E_{a}$ value. Such an increase in the dipole moment of several models can enhance the polarization term, which is a part of the well-known expression [53]:

$$
\varphi(z)=\varphi_{D}+\varphi_{R}+\varphi_{P}+\varphi_{F \mu}+\varphi_{F Q},
$$

where $\varphi(z)$ is the total energy of a physisorbed hydrogen molecule at a distance $z$ from an arbitrary adsorbent surface; $\varphi_{D}, \varphi_{R}$, represent attractive (dispersion) and repulsive energies, respectively; $\varphi_{P}, \varphi_{F \mu}$, and $\varphi_{F Q}$ are the energies of polarization, field-dipole, and field gradient-quadrupole interactions, respectively. It is worth noting that it is $\varphi_{D}$ term which adds the main contribution to $\varphi(z)$ in the case of $\mathrm{H}_{2}$ adsorption. An increase in the magnitude of $\varphi_{P}$ for some structures leads to an increase in respective $E_{a}$ values.

To illustrate the $\mathrm{H}_{2}$ /adsorbent interactions, we use IGM analysis, which has been recently proposed [41, 42]. It clearly describes non-covalent interactions between molecules, namely vdW dispersion interactions and hydrogen bonding. In the present work, we take advantage of this analysis, and clearly display the areas of non-covalent interactions in the physisorbed systems. The isosurface color maps for non-covalent interaction of hydrogen with graphene, h-BN (see Fig. 8 as an example), and the B6N6 model are shown in Fig. 9. For all adsorbents involved, it can be observed that a green isosurface region between the hydrogen molecule and the respective adsorbent exists, demonstrating the $\mathrm{vdW}$ interactions between them.

It is impossible, however, to directly assess the interaction strength by visual observation of the size and shape of isosurfaces owing to rather moderate $E_{a}$ difference. We, therefore, refer the reader to Fig. 4-Fig. 6.

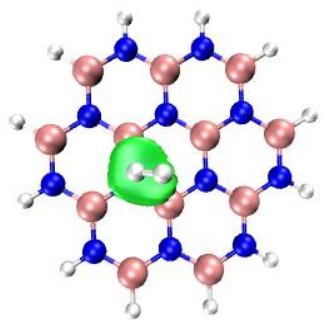

a

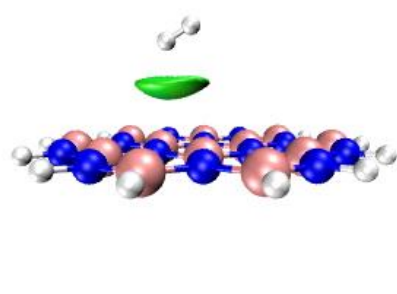

b 


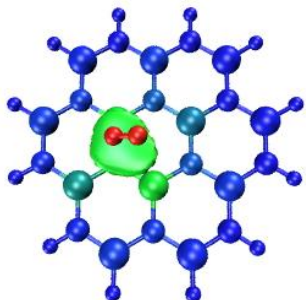

$\mathrm{c}$

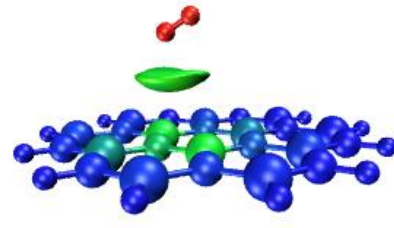

d

Fig. 8 - IGM of $\mathrm{H}_{2} / \mathrm{h}-\mathrm{BN}$ adsorption: top view (a) and side view (b). Blue atoms $-\mathrm{N}$, red atoms $-\mathrm{B}$, white atoms $-\mathrm{H}$. The non-covalent interactions area is in light green. Impact of individual atoms on non-covalent interactions: top view (c) and side view (d). Red color - the strongest impact, green - the intermediate impact, blue - minimal impact

Besides this, we use IGM analysis to establish the facts that i) the peripheral $\mathrm{H}$ atoms of the adsorbent have zero impact on the $\mathrm{H}_{2}$ /adsorbent interactions, and ii) the only underlying neighbor atoms of the adsorbent influence those interactions. The blue color of atoms indicates the marginal impact on these interactions, whereas green color denotes the stronger interplay. Red color of $\mathrm{H}$ atoms belonging to the $\mathrm{H}_{2}$ molecule reflects the strong involvement of these atoms to the interactions. One can easily see that the $\mathrm{H}$ atoms of adsorbents have little, if any, influence on the physisorbed $\mathrm{H}_{2}$ molecules, which confirms the validity of the involved models. It can be established that a particular hydrogen molecule undergoes the impact of a

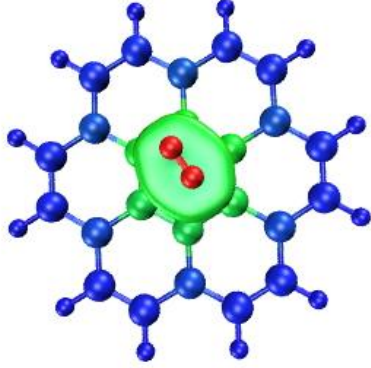

a

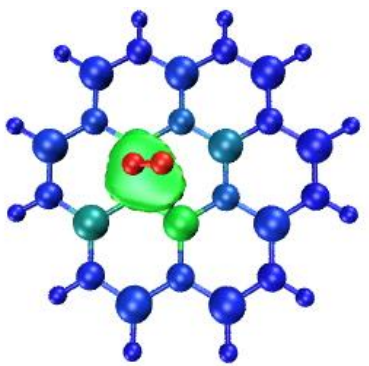

$\mathrm{b}$

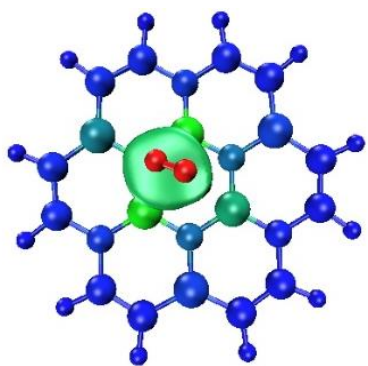

$\mathrm{c}$

Fig. 9 - IGM top view of $\mathrm{H}_{2}$ /graphene (a), $\mathrm{H}_{2} / \mathrm{h}$ - $\mathrm{BN}$ (b) and $\mathrm{H}_{2} / \mathrm{B} 6 \mathrm{~N} 6$ complex (c). Impact of individual atoms on non-covalent interactions. Red color - the strongest impact, green - the intermediate impact, blue - minimal impact

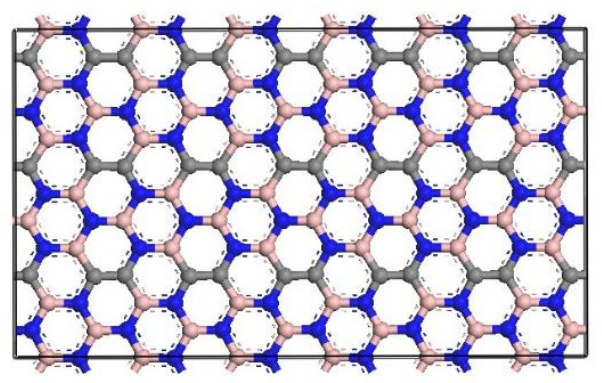

a

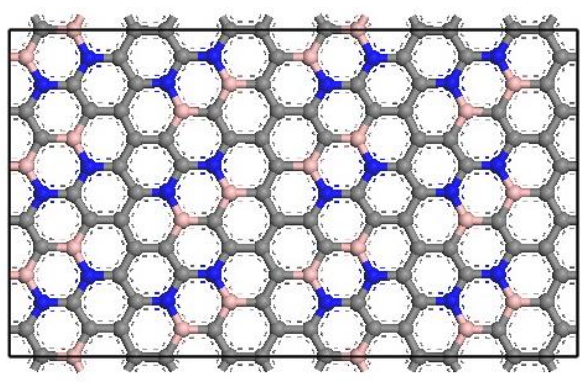

$\mathrm{b}$ 


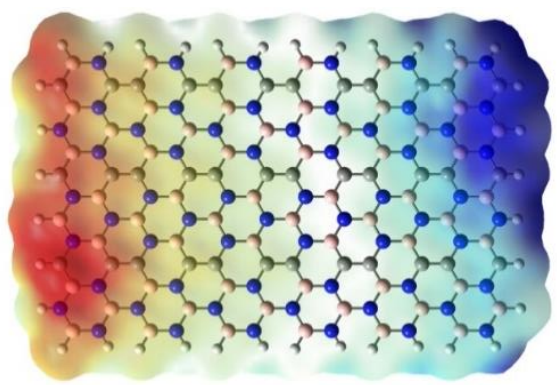

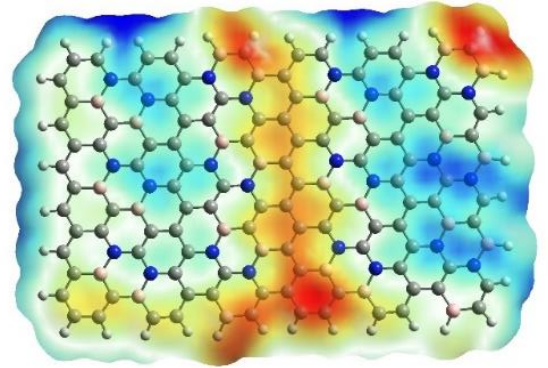

d

Fig. 10 - BNC-1 (a) and BNC-2 (b) models used for GCMC calculations. Atomic color scheme: grey - carbon, white - hydrogen, blue - nitrogen, light red - boron. EPMs for BNC-1 (c) and BNC-2 (d) models. Red and deep blue colors represent the most negative and most positive regions of electrostatic potential, respectively. Atomic color scheme: grey - carbon, white - hydrogen, blue - nitrogen, light red - boron

The main reason is the weak adsorbent/ $\mathrm{H}_{2}$ interaction due to the lack of strong binding sites. As a whole, at room temperature, the physisorption on graphene, $\mathrm{h}-\mathrm{BN}$ or GBNCH is not able to provide adsorption capacity for efficient hydrogen storage. Fig. $11 \mathrm{~b}$ shows the $\mathrm{H}_{2}$ adsorption isotherms at $T=77 \mathrm{~K}$. The difference

$\mathrm{T}=\mathbf{3 0 0} \mathrm{K}$

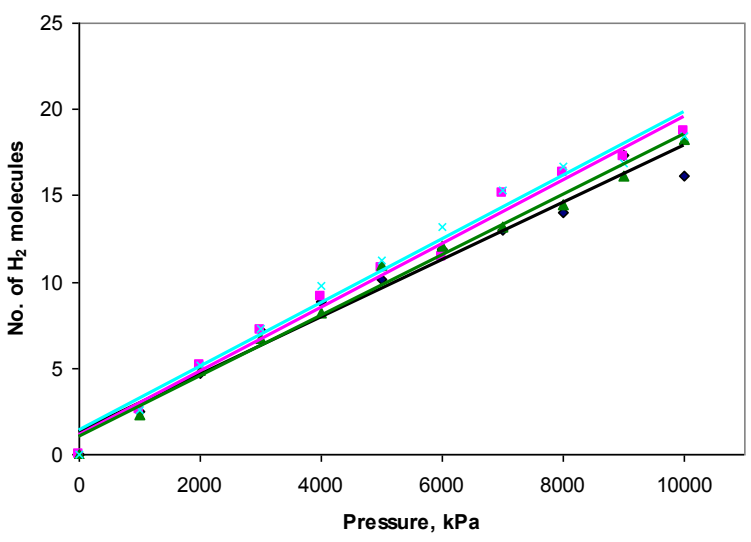

(a) $r^{2}=0.97(\bullet), 0.98(\times), 0.99(\mathbf{\Delta}), 0.99(\mathbf{\square})$

$\mathrm{T}=77 \mathrm{~K}$

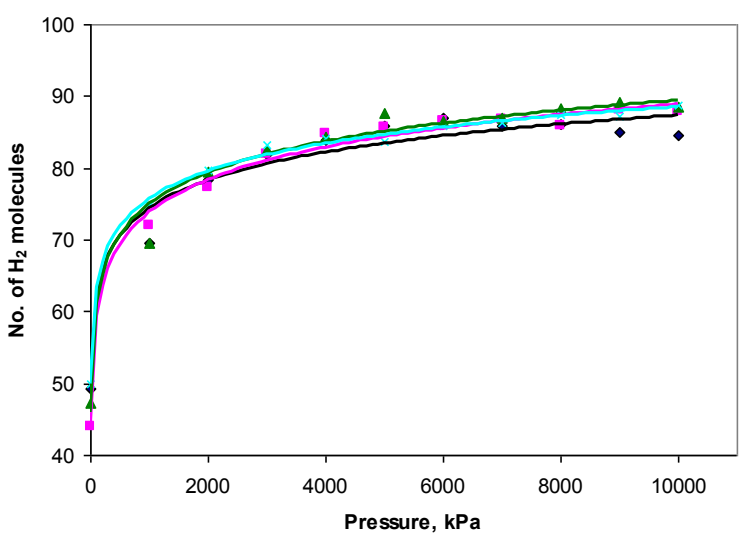

(b) $r^{2}=0.96(\bullet), 0.99(\times), 0.97(\mathbf{\Delta}), 0.99(\boldsymbol{\bullet})$

Fig. 11-Hydrogen adsorption isotherms on graphene ( $\bullet$ black), h-BN (×, light blue), BNC-1 (๘, magenta), BNC-2( $\boldsymbol{\Lambda}$, green) simulated with the GCMC method at $300 \mathrm{~K}(\mathrm{a}), 77 \mathrm{~K}$ (b), respectively. The $r^{2}$ values denote correlation coefficients between pristine models as well as BNC ones is much more expressed. Two BNCs yield the largest $\mathrm{H}_{2}$ adsorption ability among four models. For $P=10 \mathrm{MPa}$, the advantages of the newly designed models achieve $\sim 2 \%$ over h-BN, and $\sim 5 \%$ over graphene (Fig. $11 b$ ).

As we saw above, the peculiar enhancement attributed to permanent dipole-induced dipole interactions was localized in the vicinity of $\mathrm{B}$ or $\mathrm{N}$ atoms, and the increase in $\mathrm{H}_{2}$ uptake is moderate. However, in contrast to Li-, V-, Ti-decorated graphenes (see, for example, the review of Tozzini and Pelligrini [3]), there is no need for further changes in the BNCs structures. This makes it easier to use structures such as $\mathrm{H}_{2}$ storage systems.

\section{CONCLUSIONS}

All in all, we perform a DFT-D3 study of hydrogen adsorption on BNC heterostructures to explore systematically their usage as $\mathrm{H}_{2}$ adsorbents. All studied model BNC structures turn out to be stable, although they are slightly less stable than pristine coronene, representative of graphene. Descriptors related to the hydrogen storage ability of these materials: hydrogen adsorption energies $\left(E_{a}\right)$ for different positions of adsorbate molecules and the adsorbent surface, and the ability to adsorb $\mathrm{H}_{2}$ molecules at different temperatures and pressures have been obtained. As an additional measure for visualizing non-covalent interactions, an independent gradient model is used. The $\mathrm{H}_{2}$ molecules were physisorbed on all the structures considered, and adsorption was of an exothermic type. In all cases, there exist energy minima corresponding to the most favorable adsorption for certain adsorbents. We design definite BNC structures representing the maximal $E_{a}$ values. For the 'hollow' adsorption, the highest $E_{a}$ values are -5.85 (graphene) and $-6.08 \mathrm{~kJ} / \mathrm{mol}$ (B3N3). For the 'bond' adsorption, the B1N1 and B2N2 (two cases) models represent the largest $E_{a}$ values of -5.78 and $-5.45,-5.37 \mathrm{~kJ} / \mathrm{mol}$, respectively. For the 'top' adsorption, B1N1 (vertical adsorption) represents $E_{a}$ of $-5.78 \mathrm{~kJ} / \mathrm{mol}$, whereas calculated $E_{a}$ for two cases of horizontal adsorption are equal to -5.58 (B2N2) and -6.12 (B5N5) $\mathrm{kJ} / \mathrm{mol}$. The last value is the maximal among studied. The hydrogen adsorption isotherms have been obtained by the Monte-Carlo simulations. At low temperatures and high pressures, BNC-1 and 
BNC-2 nanostructures exhibit the higher $\mathrm{H}_{2}$ uptake in comparison with pristine graphene and h-BN. Finally, we believe that the present results open a new route to attain the hydrogen storage media with advanced $\mathrm{H}_{2}$ capacities.

\section{REFERENCES}

1. C. Acar, I. Dincer, J. Clean. Prod. 218, 835 (2019).

2. U.B. Demirci, P. Miele, Energ. Environ. Sci. 4, 3334 (2011).

3. V. Tozzini, V. Pellegrini, Phys. Chem. Chem. Phys. 15, 80 (2013).

4. K.S. Novoselov, A.K. Geim, S.V. Morozov, D. Jiang, Y. Zhang, S.V. Dubonos, I.V. Grigorieva, A.A. Firsov, Science, 306, 666 (2004).

5. A.K. Geim, K.S. Novoselov, Nat. Mater. 6, 183 (2007).

6. K. Milowska, M. Birowska, J.A. Majewski, Diam. Relat. Mater. 23, 167 (2012).

7. C. Changyao, J. Hone, Proc. IEEE 101, 1766 (2013).

8. J. Wang, F. Ma, W. Liang, M. Sun, Mater. Today Phys. 2, 6 (2017).

9. L.A. Falkovsky, J. Phys: Conf. Ser. 129, 012004 (2008).

10. K.M.F. Shahil, A.A. Balandin, Solid State Commun. 152, 1331 (2012).

11. G.J. Slotman, A. Fasolino, J. Phys.-Condens. Mat. 25, 045009 (2013)

12. S. Gadipelli, Z.X. Guo, Prog. Mater. Sci. 69, 1 (2015).

13. R. Amirkhani, M.H. Omidi, R. Abdollahi, H. Soleymanabadi, J. Clust. Sci. 29, 757 (2018).

14. M. Kan, Y. Li, Q. Sun, WIREs Comput. Mol. Sci. 6, 65 (2016).

15. Y. Sakai, S. Saito, M.L. Cohen, J. Phys. Soc. Jpn. 84, 121002 (2015).

16. T.H. Nguyen, D. Perilli, M. Cattelan, H. Liu, F. Sedona, N.A. Fox, C.Di Valentin, S. Agnoli, Nano Res. 12, 675 (2019).

17. S. Beniwal, J. Hooper, D.P. Miller, P.S. Costa, G. Chen, S.-Y. Liu, P.A. Dowben, E.C.H. Sykes, E. Zurek, A. Enders, ACS Nano 11, 2486 (2017).

18. E. Vessally, S. Soleimani-Amiri, A. Hosseinian, L. Edjlali, A. Bekhradnia, Appl. Surf. Sci. 396, 740 (2017).

19. M. Krieg, F. Reicherter, P. Haiss, M. Strobele, K. Eichele, M.J. Treanor, R. Schaub, H.F. Bettinger, Angew. Chem. Ger. Edit. 54, 8284 (2015).

20. S. Sanyal, A.K. Manna, S.K. Pati, J. Mater. Chem. C. 2, 2918 (2014).

21. I.K. Petrushenko, K.B. Petrushenko, Int. J. Hydrogen Energ. 43, 801 (2018).

22. L.-F. Velázquez-López, S.-M. Pacheco-Ortin, R. MejíaOlvera, E. Agacino-Valdés, J. Mol. Model. 25, 91 (2019).

23. H. Liu, C.H. Turner, Phys. Chem. Chem. Phys. 16, 22853 (2014).

24. H. Liu, C.H. Turner, J. Comput. Chem. 35, 1058 (2014).

25. J.P. Perdew, K. Burke, M. Ernzerhof, Phys. Rev. Lett. 78 , 1396 (1997).

26. J.P. Perdew, K. Burke, M. Ernzerhof, Phys. Rev. Lett. 77, 3865 (1996).

27. H.H. Ansgar Schafer, R. Ahlrichs, J. Chem. Phys. 97, 2571 (1992).

\section{ACKNOWLEDGEMENTS}

The authors acknowledge support by the IRNITU grant for scientific groups (No. 03-FPK-19).

28. F. Neese, WIREs Comput. Mol. Sci. 8, e1327 (2018).

29. S. Grimme, J. Antony, S. Ehrlich, H. Krieg, J. Chem. Phys, 132, 154104 (2010)

30. I.K. Petrushenko, K.B. Petrushenko Monatsh. Chem. 146, 1603 (2015).

31. I.K. Petrushenko, K.B. Petrushenko, Comput. Theor. Chem. 1117, 162 (2017).

32. M.D. Esrafili, S. Heidari, Comput. Theor. Chem. 1151, 50 (2019).

33. M. Sánchez, F. Ruette, Int. J. Quantum Chem. 119, e25893 (2019).

34. E. Voloshina, D. Usvyat, M. Schutz, Y. Dedkov, B. Paulus, Phys. Chem. Chem. Phys. 13, 12041 (2011).

35. M. Pykal, P. Jurecka, F. Karlicky, M. Otyepka, Phys. Chem. Chem. Phys. 18, 6351 (2016).

36. B.S.D. Frenkel, Understanding Molecular Simulation, Second Edition: From Algorithms to Applications Academic (San Diego: 1996).

37. D.J.T. M.P. Allen, Computer Simulation of Liquids, (Clarendon: Oxford: 1987).

38. A.K. Rappe, C.J. Casewit, K.S. Colwell, W.A.Goddard, W.M. Skiff, J. Am. Chem. Soc. 114, 10024 (1992).

39. Chemcraft - graphical software for visualization of quantum chemistry computations.

40. T. Lu, F. Chen, J. Comput. Chem. 33, 580 (2012).

41. C. Lefebvre, G. Rubez, H. Khartabil, J.-C. Boisson, J. Contreras-García, E. Hénon, Phys. Chem. Chem. Phys. 19, 17928 (2017)

42. C. Lefebvre, H. Khartabil, J.-C. Boisson, J. ContrerasGarcía, J.-P. Piquemal, E. Hénon, Chemphyschem. 19, 724 (2018).

43. V.V. Ivanovskaya, A. Zobelli, D. Teillet-Billy, N. Rougeau, V. Sidis, P.R. Briddon, Eur. Phys. J. B 76, 481 (2010).

44. P. Koskinen, S. Malola, H. Hakkinen, Phys. Rev. Lett. 101, 115502 (2008).

45. K. Albe, Phys. Rev. B 55, 6203 (1997)

46. A. Janotti, S.H. Wei, D.J. Singh, Phys. Rev. B 64, 174107 (2001).

47. G. Mpourmpakis, G.E. Froudakis, Catal. Today 120, 341 (2007).

48. L. Mattera, F. Rosatelli, C. Salvo, F. Tommasini, U. Valbusa, G. Vidali, Surf. Sci. 93, 515 (1980).

49. F. Costanzo, P.L. Silvestrelli, F. Ancilotto, J. Chem. Theory Comput. 8, 1288 (2012).

50. S. Grimme, J. Comput. Chem. 25, 1463 (2004).

51. M. Rubeš, O. Bludský, Chemphyschem. 10, 1868 (2009).

52. T. Heine, L. Zhechkov, G. Seifert, Phys. Chem. Chem. Phys. 6, 980 (2004).

53. R.T. Yang, Nanostructured Materials (Academic Press: 2001).

54. K. Wang, X. Wang, X. Cui, Int. J. Hydrogen Energ. 41, 7419 (2016). 


\title{
Фізсорбція водню на гетероструктурах BNC: систематичне теоретичне дослідження
}

\author{
D.V. Bogdanovich, A.I. Tsar'kova, I.K. Petrushenko
}

Irkutsk National Research Technical University, 83, Lermontov St., 664074 Irkutsk, Russia

\begin{abstract}
Ми вивчаємо адсорбцію водню на графені, гексагональному нітриді бору (h-BN) та їх BNC (боразот-вуглець) гетероструктурах за допомогою DFT. Систематично досліджуються різні комбінації залишків вуглецю та нітриду бору в одному шарі, а також вплив відношення вуглецю до BN на адсорбцію водню. Залучено теоретичний розгляд енергій адсорбції $\left(E_{a}\right)$, карти електростатичного потенціалу, незалежний аналіз градіентної моделі, а також моделювання Монте-Карло. Встановлено, що для 'hollow' адсорбції існуе незначна різниця для графену та BNCs ( 0,0 (вертикальна) та 0,1 (горизонтальна адсорбція) кДж/моль), тоді як $\mathrm{BNCs}$ демонструють достатньо вищу $E_{a}$ порівняно з h-BN (0,3 та 0,7 кДж/моль). Для досліджуваної 'top' та 'bond' адсорбції зміни е більш вираженими. Надлишок сягає 0,4 та 0,9 кДж/моль ('bond'), а також 0,8 та 1,0 кДж/моль ('top'), для графену та h-BN відповідно. Ізотерми адсорбції водню демонструють підвищене поглинання водню BNCs у порівнянні з первинними аналогами.
\end{abstract}

Ключові слова: DFT, Гетероструктура, Графен, Адсорбція, Зберігання водню. 